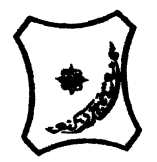

Bayero Journal of Pure and Applied Sciences, 11(2): 279 - 285

Received: July, 2018

Accepted: December, 2018

ISSN $2006-6996$

\title{
A SURVEY OF BACTERIA AND FUNGI ASSOCIATED WITH SUSPECTED CASES OF MENINGITIS AMONG CHILDREN ATTENDING SOME SELECTED HOSPITALS IN KANO
}

\author{
*Bello, S., Mohammed, B. and Muhammad, Y. \\ Department of Microbiology, Faculty of Life Sciences, Bayero University, Kano \\ Correspondence Author: safiyabello45@gmail.com; 08064816750
}

\begin{abstract}
Bacterial meningitis is one of the most potentially serious infections occurring in the Children age group, with a high incidence of acute complications and risk of long-term morbidity and mortality. The aim of the research was to Survey the Bacteria and Fungi Associated with Suspected Cases of Meningitis among Children Attending Some Selected Hospitals in Kano State, Nigeria. Three hundred samples of cerebrospinal fluids (CSF) were collected through lumbar puncture from Children aged 0-12years suspected of having Meningitis. The samples were subjected to macroscopic examination, microscopic examination, culture tests. Bacterial and fungal isolates were confirmed by biochemical tests and serology. The isolates were subjected to antimicrobial sensitivity tests using standard techniques. The results obtained were analysed and a prevalence of $8.0 \%$ was obtained for bacteria while that of fungi was $0.33 \%$. Analysis of the result according to age group showed that Children in the age group 0-2years had the highest percentage of Meningitis (7.7\%:23/300) while those in the age group 3-4 years (0.3\%:1/300) and 11-12 years had the lowest (0.3\%:1/300). However there were no significant differences between the age group and the prevalence of Meningitis (0.1042). Analysis of the result according to occurrence of isolated organism showed that gram negative Bacteria Heamophilus influenzae type b had the highest frequency of occurrence (48:12/25) while the least were Neisseria meningitidis C/W135 (4\%:1/25), Salmonella paratyphi C (4\%:1/25), Streptococcus species (Viridans group) (4\%:1/25), Candida famata (4\%:1/25). Analysis of the result in relation to the study sites showed that the highest number of positive cases were obtained from Muhammad Specialist Hospital (MMSH) (52\%:13/25) while the lowest from Aminu Kano Teaching Hospiatal (AKTH) (4\%:1/25). However there was a significant difference between the study sites and the number of positive cases (0.004). Antibiogram of the bacterial isolates showed that ceftriaxone (91.7\%:11/12) and ciprofloxacin (91.7\%:11/12) were found to be most sensitive to Haemophilus influenzae type b and least sensitive to trimethoprim sulfamethoxazole (8.3\%:1/12). The yeast, Candida famata was found to be (100\%:1/1) sensitive to ketaconazole, fluconazole, itraconazole and amphotericin B. It can be concluded that the overall prevalence of Bacteria in the study sites was $8.0 \%$ while that of fungi was $0.33 \%$. Gram negative bacteria Haemophilus influenzae type $b$ were found to be the major cause of meningitis in the study sites which are most sensitive to cefriaxone (91.7\%:11/12) and ciprofloxacin (91.7\%:11/12) and least sensitive to trimethoprim-sulfamethoxazole (8.3\%:1/12).
\end{abstract}

Keywords: Cerebrospinal fluid, Hospitals, isolates, meningitis, occurrence, paediatrics, sensitivity.

INTRODUCTION

Meningitis is an inflammation of the protective membranes covering the brain and spinal cord, known collectively as the meninges (Willey et al., 2008; CDC, 2014; Pick, et al., 2016; Hasbun, 2017). The inflammation may be caused by infection with viruses, bacteria, fungi, and parasites (Reid and Fallon, 1992; Ginsberg, 2004; Cha'vez-Bueno and McCracken, 2005; Willey et al., 2008; Hasbun, 2017).

Bacterial Meningitis is one of the most potentially serious infections in infants and older Children because it is associated with a high rate of acute complications, risk of long-term morbidity and mortality (HudeckovaIde et al., 2010; Ide and Awopeju, 2015; Muller, 2016; Pick et al., 2016; Hasbun, 2017). Fungal Meningitis is rare in the pediatric population but may occur in immunocompromised such as Children with cancer, previous neurosurgery, or cranial trauma or premature infants with low birth rates (Mann and Jackson, 2008; Faust, 2015; CDC, 2016).

Kano state of Nigeria in sub- Saharan Africa is located in the Meningitis belt where seasonal meningococcal epidemics occur during the dry season (Sultan et al., 2005; WHO, 2015; CDC, 2014; Abdussalam et al., 2014). Despite the advancement in diagnosis and treatment of infectious diseases, meningitis is still considered as an important cause of mortality and morbidity, especially in the Children population (Tacon and Flower, 2012; Águeda et al., 2013: Abdulkareem et al., 2014). 
BAJOPAS Volume 11 Number 2 December, 2018

Therefore, a regular surveillance of the etiology and their antibiotic susceptibility is imperative for appropriate case management and infection control. The aim of the research was to Survey the Bacteria and Fungi Associated with Suspected Cases of Meningitis among Children attending Aminu Kano Teaching Hospital (AKTH), Murtala Muhammad Specialist Hospital (MMSH) and Hasiya Bayero Pediatric Hospital (HBPH) in Kano, State.

\section{MATERIALS AND METHODS \\ Study Area}

Three hospitals were selected for the study include; Aminu Kano Teaching Hospiatal (AKTH) located in Tarauni Local Government Area of Kano State, Murtala Muhmmad Specialist Hospital (MMSH) and Hasiya Bayero Pediatric Hospital (HBPH) in Municipal Local Government Area of Kano State, located at latitude $10^{\circ} 33 \mathrm{~N}$ to $11^{\circ} 15 \mathrm{~N}$ and longitude $34^{\circ} \mathrm{CE}$ to $8^{\circ}$ 20CE (NPC, 2006).The Hospitals were strategically located for access to both urban and rural population from the 44 Local Governments Areas of Kano State.

\section{Study Population}

The study population comprised of Children with suspected cases of Meningitis attending Aminu Kano Teaching Hospital (AKTH), Murtala Muhmmad Specialist Hospital (MMSH) and Hasiya Bayero Paediatric Hospital (HBPH) in Kano State.

\section{Inclusion Criteria}

Children of both sexes aged 0-12years with suspected cases of Meningitis whose parents or caregivers consented were enrolled for the study.

\section{Exclusion Criteria}

Non- consenting parents or caregivers of Children from both sexes aged 0-12 years and Children above 12 years were excluded in the study.

\section{Sample Size Determination}

Sample size was 200 obtained using the formular below

Where; (Lwanga and Lemeshow, 1991)

$\mathrm{N}=$ minimum sample size

$\mathrm{z}=$ point of normal distribution curve equivalent at $95 \%$ (1.960) confidence interval

$q=$ complementary probability of $q=1-p$

$\mathrm{p}=$ prevalence rate from previous work $=13.7 \%$

(Mado et al., 2013)

$\mathrm{d}=$ degree of precision margin of error $=0.05$

$\mathrm{N}=(1.960) 2 \times 0.137 \times(1-0.137)$

(0.05) 2

$=3.8416 \times 0.137 \times 0.863$

0.0025

$=0.454196209637$

0.0025

$=181.67848384$

$\mathrm{N}=181$

Based on the local prevalence obtained by Mado et al., 2013, the minimum sample size obtained was 181 which were rounded up to 300 to minimize error.

\section{Sample Collection}

A total of 300 cerebrospinal fluid were collected by the clinician through lumbar puncture from Children with suspected cases of meningitis.
Macroscopic Examination of Cerebrospinal Fluid Cerebrospinal fluid (CSF) samples were observed macroscopically to determined the presence of turbidity, blood, pigment and clots (Cheesbrough, 2010).

\section{Latex Agglutination Test}

Directigen $^{T M}$ Meningitis combo Test is a presumptive Latex Agglutination test for the direct qualitative detection of antigens to Haemophilus influenzae type b, Streptococcus pneumoniae, Escherichia coli, group B Streptococcus and Neisseria meningitis group A, B, C, Y, or W135 in Cerebrospinal fluid.

The test was conducted using (BD Directigen ${ }^{\text {TM }}$ Ireland-0214011JAA) test kit according to Manufacturer's instruction. A drop of positive control was dispensed onto circles 1 through 6 of row, negative control onto circles 1 through 6 of row and 50 microlitre of test sample (CSF) was dispensed onto circles 1 through 6 of sample rows and in circles labeled " $\mathrm{A}$ " and " $\mathrm{B}$ " on the test card. Rows positive and negative are used for control. Reagent $A$ (control latex suspension) was dispense onto the " $A$ " Circle, Reagent " $B$ " (control latex suspension) onto the " $B$ " circle. A drop of latex suspension Reagent 1 was dispensed onto the circle in column 1, rows positive, negative and sample. The procedure was repeated for the remaining latex suspensions (Reagent 2-6) in rows positive, negative and sample columns. The samples and latex reagents in each circle were mixed with a different plastic stirrer then placed on a rotator at a speed of $12 \mathrm{rpm}$ for $10 \mathrm{mins}$ and read immediately under a high intensity incandescent light. Positive test shows agglutination. Any degree of agglutination present in one of the latex reagents indicates the presence of corresponding antigen.

Agglutination in two or more latex reagents or the corresponding Reagent A (Reagent 1-5) or Reagent B (Reagent 6) renders the reaction uninterpretable. Negative test shows no agglutination. Positive control yield strong agglutination within 10 minutes, negative control shows no agglutination. Agglutination in any of the negative control circles renders the reaction uninterpretable.

Microscopic Examination of Cerebrospinal Fluid Gram Staining and Auramine-Phenol Fluorochrome Staining for the Detection of Mycobacterium tuberculosis were carried out (Cheesbrough, 2010).

\section{Culture}

A centrifuged sediment of cerebrospinal fluid was inoculated onto blood agar, chocolate agar, MacConkey for bacterial culture and Sabauroud dextrose agar for fungal culture (Cheesbrough, 2010). Colonies observed were further characterized by Gram staining, biochemical tests and serological tests.

\section{Identification of Isolates}

For identification of Gram Positive Cocci; Catalase, Optochin Sensitivity and Bile Solubility were carried out (Cheesbrough, 2010).

For identification of Gram Negative Cocco Bacilli; identification of Growth Factor Requirement Using $X$, $\mathrm{V}$, and $\mathrm{X}+\mathrm{V}$ Discs was carried out (Cheesbrough, 2010) 
BAJOPAS Volume 11 Number 2 December, 2018

For identification of Gram Negative Diplococci, Oxidase test was carried out (Cheesbrough, 2010). For identification of Gram Negative Bacilli; Analytical profile index (API 20E) Test for the precise identification of Gram negative bacteria was carried out. The test was conducted using Biomerieux (France-07584J) test kit according to Manufacturer's instruction. An incubation box (tray and lid) was prepared and about $5 \mathrm{ml}$ of distilled water was placed into the honey combed wells of the tray to create a humid atmosphere and the strip was removed from its pack and placed in the incubation box. A single well isolated colony from MacConkey agar plate was removed and inoculated into a sterile distilled water to achieve turbidity comparable to $0.5 \mathrm{McF}$ arland Standard.

The cupules were filled with the bacterial suspension by placing the tip of the pipette against the side of the cupules to avoid formation of bubbles until a flat or slightly convex surface was obtained. Sterile mineral oil was added to the cupules labeled lysine decarboxylase (LDC), Onithine decarboxylase (ODC), Arginine dihydrolase (ADH), Hydrogen sulphide (H2S) and Urease (URE). The lid of the incubation chamber was placed over the bottom and labeled after which it was incubated at $37^{\circ} \mathrm{C}$ for 24 hours after which the appropriate reagents were added to their respective compartments: one drop of Kovac's to the indole (IND) (read within a couple of minutes), one drop of Barritt's A and B to Voges-Proskauer ( VP ) (reaction may take up to 10 minutes) and one drop of $\mathrm{FeCl} 3$ toTryphtophane deaminase (TDA) after which it was observed for colour change within minutes. A pink or red colour indicate positive result. The strips were read according to ATCC (American type culture collection) Escherichia coli.

Identification was achieved using numerical profile. On the result sheet, the tests were separated into groups of 3 and a value 1,2 or 4 is indicated for each on the result sheet and by adding together the values corresponding to positive reactions within each group, a 7-digit profile number is obtained for the 20 tests of the API $20 \mathrm{E}$ strip. Identification was performed with the identification software (www.apiweb.com ) by entering the 7-digit numerical profile manually through the keyboard. Salmonella species were further confirmed by serology

\section{Serotyping of Gram Negative Bacteria}

The test was conducted using BD Difco ${ }^{\mathrm{TM}}$ (Ireland8085889) test kit according to Manufacturer's instruction. A wooden applicator stick was used to remove a colony from an overnight culture on Macconkey agar plate and emulsified first with Difco ${ }^{T M}$ Salmonella O Antiserum poly A-I and Vi which is used to screen possible Salmonella isolates .The presence of agglutination indicate that a further serological test was needed to identify the isolate using Difco ${ }^{\mathrm{TM}}$ Salmonella O antisera; each antiserum is specific for certain serogroup antigen: they include; Difco ${ }^{\mathrm{TM}}$ Salmonella O Antiserum Group C1 Factor 6, 7; Difco $^{\mathrm{TM}}$ Salmonella O Antiserum Group E1 Factor1,3; Difco ${ }^{\mathrm{TM}}$ Salmonella O Antiserum Factor 2; Difco ${ }^{\mathrm{TM}}$ Salmonella O Antiserum Factor 9; Difco ${ }^{\mathrm{TM}}$ Salmonella $\mathrm{O}$ Antiserum Group Factor 4, 5. Presence of agglutination shows a positive test for Salmonella. Factor 6, 7 agglutinate
Group C Salmonella, Factor 3, 10 agglutinate Group E1 Salmonella, Factor 9 agglutinate Group D Salmonella, Factor 2 agglutinate Group A Salmonella, Factor 4, 5 agglutinate Group B Salmonella.

\section{Identification of Isolated Yeast}

Indian Ink test for the identification Cryptococcus neoformans, Germ tube test for the identification of Candida albicans were carried out (Cheesbrough, 2010). Analytical profile index Auxillary (API 20 C AUX) test for the precise identification of the most frequently encountered yeasts was carried out .The test was conducted using Biomerieux (France$07628 \mathrm{H}$ ) test kit according to Manufacturer's instruction. An incubation box (tray and lid) was prepared and about $5 \mathrm{ml}$ of distilled water was placed into the honey combed wells of the tray to create a humid atmosphere and the strip was removed from its pack and placed in the incubation box. A single well isolated yeast colony from Sabouraud Dextrose Agar culture plate an overnight culture was removed and inoculated into a sterile distilled water to achieve turbidity comparable to 2.0 McFarland Standard after which $100 \mu \mathrm{l}$ of the yeast suspension was dispensed into an ampoule of API C Medium and mixed while avoiding the formation of bubbles. The cupules were filled with the suspension obtained in the ampoule of API C AUX medium containing the test organism by placing the tip of the pipette against the side of the cupules to avoid the formation of bubbles until a flat or slightly convex surface was obtained. The lid of the incubation chamber was placed over the bottom after which it was labeled and incubated at $29^{\circ} \mathrm{C}$ for 72 hours as directed by the manufacturer. The cupules were pre-coated with sugars except the first cupule that served as control. After incubation, growth in each cupule was compared with the control. A cupule more turbid than the control was recorded in the result sheet as a positive reaction. Identification was obtained with the numerical profile. On the result sheet the tests were separated into groups of 3 and a value 1,2 or 4 is indicated for each. By adding the numbers corresponding to positive reactions within each group, a 7-digit number is obtained which constitutes the numerical profile. Identification was performed using the identification software by entering the 7-digit numerical profile manually through the keyboard (www.apiweb.com where yeast species are provided with codes that correspond to excellent, very good, good and acceptable identification.

\section{Susceptibility Test}

The isolates were standardized using $0.5 \mathrm{McF}$ arland turbidity Standard.

Bacterial Susceptibility Test

Antimicrobial susceptibility test was carried out on the bacterial isolates using a modified Kirby-Bauer method (Bauer et al., 1966). A loopful of the suspension was aseptically transferred onto the centre of chocolate agar or blood agar (fastidious organisms), Mueller Hinton agar (non-fastidious organisms) after which a sterile swab was used to evenly Streak over the surface of the medium in three directions, rotating the plate approximately $60^{\circ} \mathrm{C}$ after each inoculation to ensure even distribution of the inoculum and confluent growth of the bacteria. 
A sterile forcep was used to evenly distribute the antibiotic discs; Tetracycline $(30 \mu \mathrm{g})$, ciprofloxacin $(5 \mu \mathrm{g})$, ceftriaxone $(30 \mu \mathrm{g})$, gentamicin $(30 \mu \mathrm{g})$, chloramphenicol $(30 \mu \mathrm{g})$, amoxicillin-clavulanic acid $(30 \mu \mathrm{g})$, and trimethoprimsulfamethoxazole $(1.25 / 23.75 \mu \mathrm{g})$ and oxacillin $(1 \mu \mathrm{g})$. The plates were incubated aerobically (Mueller-Hinton agar) or anaerobically (chocolate agar or blood agar) at $37^{\circ} \mathrm{C}$ for 24 hours. After overnight incubation, a ruler was used on the underside of the plate to measure the diameter of each zone of inhibition in $\mathrm{mm}$ (Cheesbrough, 2010; CDC, 2016). The results were recorded and compared with the zone diameter interpretive standards of the Clinical Laboratory Standards Institute (CLSI, 2015).

\section{Fungal Susceptibility Test}

Disc diffusion method using locally prepared antifungal single disc according to the method of Rasco (2011) was carried out on the yeast isolate . The antifungal solutions were prepared at the Drug and Manufacturing Unit of Aminu Kano Teaching Hospital using ketaconazole tablets; fluconazole capsule (Diflucan), itraconazole capsule (Itacare) and amphotericn B powder for injection (Amfocare) obtained from pharmaceutical stores. The drugs were dissolved in $100 \mathrm{ml}$ of their respective solvents to arrive at the desired concentration $20 \mu \mathrm{L}$ required to impregnate blank sensitivity discs (oxoid antimicrobial sensitivity testing disc).

A loopful of the suspension was aseptically transferred onto the centre of Mueller Hinton agar containing 2\% glucose and $0.5 \mu \mathrm{g} / \mathrm{ml}$ methylene blue. The glucose supports the growth of Candida species while methylene blue enhanced zone and edge clarity (CLSI, 2008; Rasco, 2011). A sterile swab was used to evenly Streak over the surface of the medium in three directions, rotating the plate approximately $60^{\circ} \mathrm{C}$ after each inoculation to ensure even distribution of the inoculum and confluent growth of the yeast. A sterile forcep was used to evenly distribute the appropriate antifungal discs; ketaconazole $(15 \mu \mathrm{g})$; fluconazole $(25 \mu) \mathrm{g}$, itraconazole $(10 \mu \mathrm{g})$ and amphotericn B $(10 \mu \mathrm{g})$. The plates were incubated aerobically at $37 \mathrm{oC}$ for 48 hours. After incubation, a ruler was used on the underside of the plate to measure the diameter of each zone of inhibition in $\mathrm{mm}$ (Cheesbrough, 2010). The results were recorded and compared with the zone diameter interpretive standards of Rasco, 2011 .

\section{Data Analysis}

Data obtained were compiled in Excel and analyzed using SPSS Version 20.0. Associations between variables were determined by Chi square, $P$ value $<0.05$ was set as an indicator of statistical significant.

\section{RESULTS AND DISCUSSION}

The study revealed that out of the 300 cerebrospinal fluid samples, 25 samples yielded positive growth resulting in a prevalence of $8.33 \%$ which is lower than $13.7 \%$ recorded in a retrospective study in Zamfara State (Mado et al., 2013). However the prevalence was higher than those reported from Abuja 5.2\% (Iregbu and Abdullahi, 2015 and Port Harcourt 1.83\% (Ide and Awopeju, 2015). These differences may be due to the type of study; while this study is prospective all the other studies cited above were retrospective. Other factors may be due to differences in methodology as well (Table1).

The study showed that gram negative bacteria were the major cause of Meningitis in the study sites; Haemophilus influenzae (Hib) (48:12/25) Salmonella species $16 \%$, Neisseria meningitidis (4\%:1/25) while $28 \%$ were caused by Gram positive pathogens ; Streptococcus species (Viridans group) (4\%:1/25), Streptococcus pneumoniae $(24 \%: 6 / 25)$ and $4 \%$ by yeast Candida famata (4\%:1/25) (Table 2), which is contrary to the findings of a retrospective study reported from Abuja by Iregbu and Abdullahi, (2015) where they reported Gram positive pathogens ( $S$. aureus 32.2\%, Streptococcus pneumoniae $17.6 \%$, Enterococci feacalis $7.2 \%$ ), to be slightly higher $57 \%$ as the etiologic agents of meningitis and Gram negative of $43 \%$. (Neisseria meningitidis 3.6\%, Escherichia coli 14.3\%, Klebsiella pneumoniae 21.5\%, Haemophilus influenzae 3.6\%); Ide and Awopeju (2015) in Port Hartcourt also reported Gram-positive cocci $75 \%$ (S. aureus, 66.67\%; Group B Streptococcus, $8.3 \%$ ), Gram-negative bacilli $16.67 \%$ (Escherichia coli 16.67\%) and C. neoformans 8.33\%. Mashouf et al., (2014) in Iran also reported 58.9\% Gram-positive cocci and $41.1 \%$ Gram-negative bacilli. The high incidence of Haemophilus influenzae in Children less than 5 years in this study agreed with the report, which states that Haemophilus influenzae mainly causes acute bacterial meningitis (ABM) in Children older than 3 month and less than 5 years (Sáez-Llorens and McCracken, 2003 ; Cheesbrough, 2010; CDC, 2014).

The study revealed Neisseria meningitidis was isolated from an 11year old Child which is similar to the findings of Iregbu and Abdullahi (2015) from Abuja, who isolated Neisseria meningitidis in a child above 6year old, this could be attributed to the fact that immunization to the disease should have been completed at this age group, therefore the prevalence of Neisseria meningitidis could be as a result of epidemics.

The only fungal agent isolated in this study was Candida famata $(4.0 \%: 1 / 25)$ which was isolated from a four month old HIV negative infant which might indicate weak immune system. Similarly Candida famata had been reportedly isolated from CSF in South Africa as published in a case report in a 29 year old whose immune status could not be confirmed due to death of the patient by Prinsloo and Weldhagen, (2003). This finding disagrees with the findings of Ide and Awopeju (2015) where they reportedly isolated Cryptococcus neoformans $8.33 \%$ from an immunosuppressed (HIV infected) Child.

The study also revealed that Children in the age group 0-2years had the highest percentage of Meningitis (7.7\%:23/300) while those in the age group 3-4 years and 11-12 years had the lowest $(0.3 \%: 1 / 300)$. The high prevalence of Meningitis in the aged group 0-2years could be attributed to immaturity of their immune system. However there was no significant differences between the age group and the prevalence of Meningitis (0.1042) (Table 1). However the Null hypothesis is accepted. 
Although the study findings revealed that MMSH had the highest number of isolated organisms with 13 $(52 \%)$ and the least was AKTH $1(4 \%)$. However there was a significant difference between the study sites and the number of positive cases (0.004). However the Alternate hypothesis is accepted (Table 3).The high prevalence of Meningitis causing organisms at
MMSH could be attributed to the fact that MMSH is largely patronized by low income earners that might be living in an overcrowded environment that may not be well ventilated when compared to AKTH which is largely patronized by high income earners who are living in a well ventilated environment.

Table 1: Distribution of Age Group among Children with Suspected Cases of Meningitis in Relation to number of positive cases

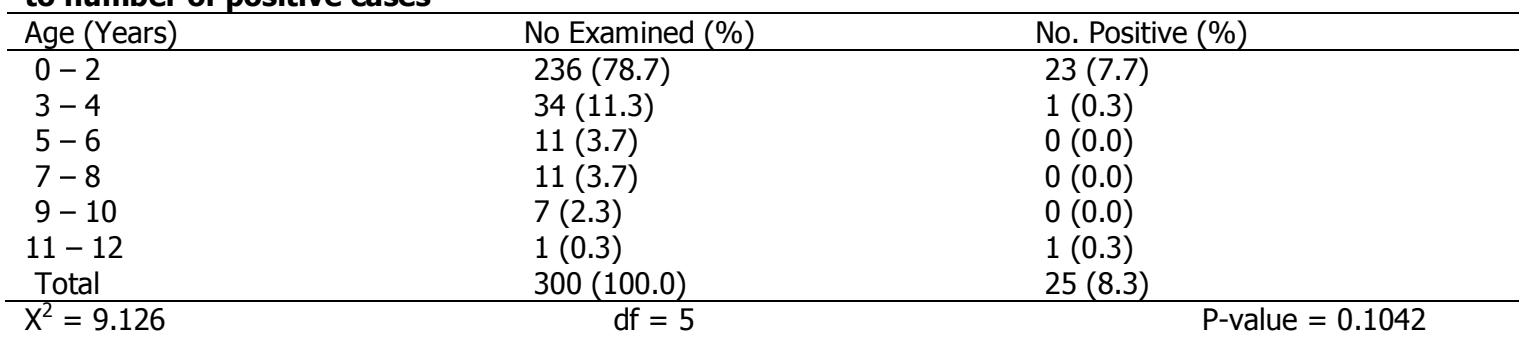

Table 2: Distribution of Bacterial and Fungal Isolates among Children with Suspected Cases of Meningitis

\begin{tabular}{lll}
\hline Isolated Organisms & Frequency & Percent \\
\hline Heamophilus influenzae & 12 & 48.0 \\
Neisseria meningitidis & 1 & 4.0 \\
Salmonella typhi & 3 & 12.0 \\
Salmonella paratyphi C & 1 & 4.0 \\
Streptococcus pneumoniae & 6 & 24.0 \\
Streptococcus species (Viridans group) & 1 & 4.0 \\
Candida famata & 1 & 4.0 \\
Total & 25 & 100.0 \\
\hline
\end{tabular}

Table 3: Distribution of Positive cases of Meningitis in Relation to Study Sites

\begin{tabular}{lcccc}
\hline \multicolumn{1}{c}{ Culture } & Study Site & Total \\
& AKTH & HBPH & MMSH & 25 \\
Growth & 1 & 11 & 13 & 275 \\
No Growth & 99 & 89 & 87 & 300 \\
Total & 100 & 100 & 100 & P- value $=0.004$
\end{tabular}

Key: $\quad$ AKTH: Aminu Kano Teaching Hospital; HBPH: Hasiya Bayero Pediatric Hospital MMSH: Murtala Muhammad Specialist Hospital

Analysis of the result in relation to the distribution of positive and negative cases of bacteria and fungi among Children with suspected cases of Meningitis, showed that bacteria $(24 / 25)$ had the highest number of positive cases while Fungi $(1 / 25)$ had the least (0.01) (Table 4). However there was a significant difference between bacteria and fungi among the study population. However the Alternate hypothesis is accepted.

Antibiogram of bacterial isolates showed that Ceftriaxone (91.7\%:11/12) and ciprofloxacin (91.7\%:11/12) were found to be most sensitive to Haemophilus influenzae and least sensitive to trimethoprim-sulfamethoxazole $\quad(8.3 \%: 1 / 12)$ (Table
5). Neisseria meningitidis was found to be $100 \%$ susceptible to ceftriaxone, chloramphenicol and ciprofloxacin which completely agrees with the work of Mado et al. (2013) where they reported Neisseria meningitidis to be $100 \%$ susceptible to ceftriaxone $(30 \mu \mathrm{g})$, Chloramphenicol $(30 \mu \mathrm{g})$ and ciprofloxacin $(5 \mu \mathrm{g})$ antibiotics.

Candida famata was found to be $100 \%$ sensitive to ketoconazole, fluconazole, itraconazole and amphotericn B (Table 6), which is similar to the findings of Prinsloo and Weldhagen, (2003), which showed ketaconazole $(15 \mu \mathrm{g})$; fluconazole $(25 \mu \mathrm{g})$ itraconazole $(10 \mu \mathrm{g})$ and amphotericin B $(10 \mu \mathrm{g})$ to be $100 \%$ active against Candida famata.

Table 4: Distribution of Positive cases of Bacteria and Fungi Among Children with Suspected Cases of Meningitis

\begin{tabular}{|c|c|c|c|}
\hline Organism & Positive & Negative & Total \\
\hline Bacteria & 24 & 276 & 300 \\
\hline Fungi & 1 & 299 & 300 \\
\hline Total & 25 & 575 & 600 \\
\hline
\end{tabular}


BAJOPAS Volume 11 Number 2 December, 2018

Table 5: Antibiogram of bacterial isolates

\begin{tabular}{|c|c|c|c|c|c|c|c|c|c|}
\hline Test Organism & $\begin{array}{l}\text { No. } \\
\text { tested }\end{array}$ & $\begin{array}{l}\text { CRO } \\
\mathrm{n}(\%)\end{array}$ & $\begin{array}{l}\text { CIP } \\
\mathrm{n}(\%)\end{array}$ & $\begin{array}{l}\text { SXT } \\
\mathrm{n}(\%)\end{array}$ & $\begin{array}{l}\mathrm{CHL} \\
\mathrm{n}(\%)\end{array}$ & $\begin{array}{l}\mathrm{CN} \\
\mathrm{n}(\%)\end{array}$ & $\begin{array}{l}\text { TET } \\
\mathrm{n}(\%)\end{array}$ & $\begin{array}{l}\text { AMC } \\
\mathrm{n}(\%)\end{array}$ & $\begin{array}{l}\text { OX } \\
\text { n (\%) }\end{array}$ \\
\hline $\begin{array}{l}\text { Heamophilus } \\
\text { influenzae (Hib) }\end{array}$ & 12 & $11(91.7)$ & $11(91.7)$ & $1(8.3)$ & $9(75.0)$ & - & $8(66.6)$ & $8(66.7)$ & - \\
\hline S. pneumonae & 6 & & & $1(16.7)$ & $5(83.3)$ & & $3(50.0)$ & & $4(66.7)$ \\
\hline Salmonella typhi & 3 & $3(100)$ & $1(100)$ & $2(66.7)$ & $2(66.7)$ & $3(100)$ & $0(0.0)$ & $2(66.7)$ & 5 \\
\hline $\begin{array}{l}\text { Salmonella } \\
\text { paratyphic }\end{array}$ & 1 & $1(100)$ & $1(100)$ & $0(0.0)$ & $0(0.0)$ & $1(100)$ & $0(0.0)$ & $1(100)$ & - \\
\hline $\begin{array}{l}\text { Neisseria } \\
\text { meningitidis } \\
(\mathrm{C} / \mathrm{W} 135)\end{array}$ & 1 & $1(100)$ & $1(100)$ & $0(0.0)$ & $1(100)$ & - & - & - & - \\
\hline $\begin{array}{l}\text { Streptococcus } \\
\text { species } \\
\text { (Viridans group) }\end{array}$ & 1 & $0(0.0)$ & - & - & $1(100)$ & - & $1(100)$ & - & - \\
\hline Total & 24 & $16(66.7)$ & $14(58.3)$ & $4(16.7)$ & $18(75)$ & $4(16.7)$ & $12(50)$ & $11(45.8)$ & $4(16.7)$ \\
\hline
\end{tabular}

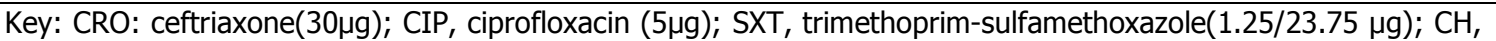

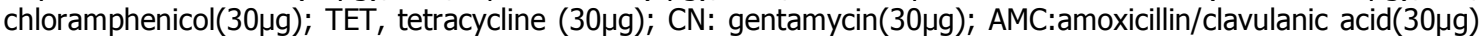
and oxacillin $(1 \mu \mathrm{g}) . \mathrm{n}=$ number of individual organisms isolated.

Table 6: Antibiogram of Fungi to Commercially Available Antifungal

$\begin{array}{lclll}\text { Antimicrobial agents } & \text { No. of fungus sensitive } & & \\ \text { Candida famata } \mathrm{n}= & & & \\ & & & \\ \text { KET }(15 \mu \mathrm{g}) & 1(100.0) & & \\ \text { AMP B }(10 \mu \mathrm{g}) & 1(100.0) & & \\ \text { ITRA }(10 \mu \mathrm{g}) & 1(100.0) & & \\ \text { FLU }(25 \mu \mathrm{g}) & 1(100.0) & & \\ \text { Key: KET: ketoconazole }(15 \mu \mathrm{g}) ; & \text { AMP B: amphotericin } \quad \text { B }(10 \mu \mathrm{g}) ; \quad \text { FLU: fluconazole }(25 \mu \mathrm{g}) \text {, }\end{array}$

ITRA: itraconazole $(10 \mu \mathrm{g})$

\section{CONCLUSION AND RECOMMENDATION}

It can be concluded that the overall prevalence of bacteria in the study sites was $8.0 \%$ while that of fungi was $0.33 \%$. Gram negative bacteria Haemophilus influenzae type b were found to be the major cause of Meningitis which are most sensitive to cefriaxone(30 $\mathrm{g}$ ) (91.7\%:11/12) and ciprofloxacin

\section{REFERENCES}

Abdulkareem et al., M. A., Shmeylan, A., Abdulmalik, M. A., Saleh A., Lolowa A. and Nabil K. (2014) Review Bacterial Meningitis: An update review. African Journal of Pharmacy And Pharmacology, 8(18) 469-478

Abdussalam A.F.; Monaghan A.J; Dukic V.M.; Hayden M.H., Hopson T.M; Leckebusch G.C. and Thornes, J.E. (2014). Climate Influences on Meningitis Incidence in Northwest Nigeria 6: 62-63.

Águeda, S., Campos, T. and Maia, A. (2013). Prediction of Bacterial Meningitis based on cerebrospinal fluid pleocytosis in Children. Brazilian Journal of Infectious Diseases, 17 (4)

Bauer, A. W., Kirby, W. M. and Sherries, J. K. (1996). Antibiotic Susceptibility Testing by a Standard single disc method. American Journal of Clinical Pathology. 45:493-496

Centre for Disease Control and prevention (2014). Laboratory Methods for the Diagnosis of Meningitis Caused by Neisseria meningitidis, Streptococcus pneumoniae and

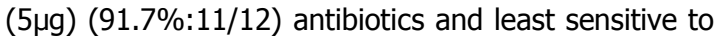
trimethoprim-sulfamethoxazole $\quad(1.25 / 23.75 \mu \mathrm{g})$ $(8.3 \%: 1 / 12)$. It can be recommended that the use of commercially available antibiotics such as ciprofloxacin $(5 \mu \mathrm{g})$ and ceftriaxone $(30 \mu \mathrm{g})$ should be employed for the empirical treatment of bacterial Meningitis.

Haemophilus influenza, 2nd Edition. Retrieved 04 July 2016.

Centre for Disease Control and prevention (2016). Whole-Genome Characterization of Epidemic Centre for Disease Control and prevention (2016). Fungal Meningitis. https://www.cdc.gov/meningitis/fungal.htm/ Retrieved 04 July 2017

Cha'vez-Bueno, S. and McCracken, G. H. (2005). Bacterial Meningitis in Children. Pediatric Clinics of North America. 52:795- 810.

Cheesbrough, M. (2010). District laboratory practice in tropical countries. Part 2 Cambridge University press U.K.pp116-124,163164,175-176,202-203, 243-245.

Clinical and Laboratory Standards Institute (2015). Performance Standards for Antimicrobial Susceptibility Testing M100-S25, 35 (3).

Clinical and Laboratory Standards Institute (CLSI) (2008). Method for antifungal disc diffusion susceptibility testing of yeasts. Approved Standard M44-A2

Faust, S.N. (2015). Pediatric Aseptic Meningitis. emedicine.medscape.com/article/972179overview. Retrieved 04 July 2017. 
Ginsberg, L. (2004). "Difficult and recurrent meningitis". Journal of Neurology, Neurosurgery, and Psychiatry, 75: 16-21.

Hasbun, R. (2017). Meningitis. https://emedicine.medscape.com/article/232 915-overview. Retrieved 04July 2017

Hudeckova, H., Jesenak, M., Maria, A., Svihrova, V., and Banovcin, P., (2010). National Analysis of Bacterial Meningitis in Slovakia, 19972007. Public Health Reports, 125(1):129136.

Ide, Y. L. and Awopeju, A. T. (2015). Bacterial Isolates and Antibiogram of Cerebrospinal Fluid of Paediatric Patients as Seen at the University of Port Harcourt Teaching Hospital Journal of pharmaceutical and Biomedical sciences, 5(2)4-9.

Iregbu, K. C. and Abdullahi, N. (2015). Profile of acute bacterial meningitis isolates in Children in National Hospital, Abuja. Nigerian Medical Journal, 56:297-300

Mado, S. M., Abubakar, U., Onazi, S. O. and Adeoye, G. O. (2013). Epidemic cerebrospinal Meningitis in Children at Federal Medical Centre, Gusau, Zamfara State, Nigeria. Nigerian Journal Of Paediatrics. 40(2):169171.

Mann, K. and Jackson, M. A. (2008). Pediatrics in Review. Journal of the American Academy of Pediatrics.29:417-430.

Mashouf, Y. R., Esmaeili, R. and Moshtaghi A. (2014). Study of Bacterial Agents of Meningitis in Children and Detection of Their Antibiotic resistance Patterns in Hamadan, Western Iran. International Journal of Medical Investigation. 3(1):18-24.

Muller, M. L. (2016).Pediatric Bacterial Meningitis.emedicine.medscape.com/article/9 61497- overview\#a5. Retrieved 4 July 2017.

Ochei, J. and Kolhatkar, A. (2007). Medical Laboratory Science Theory and Practice. Published by
Tata McGraw-Hill Publishing Company Limited New Delhi. Pp. 626-627.

Pick, A. M., Sweet, D. C., and Begley, K. J. (2016). A Review of Pediatric Bacterial Meningitis. United State Pharmacist, 41(5): 41-45.

Prinsloo, B. and Weldhagen, G. F., (2003). Isolation of Candida famata as a cause of human central nervous system infection. South African Medical Journal, 93 (8):601.

Rasco, (2011). Susceptibility Testing of Yeasts, Agar Diffusion Method with Neo-Sensitabs. Available from http://www.rosco.dk/gfx/pdf/yeasts.pdf Retrieved April 052016.

Reid, H. and Fallon, R.J. (1992). Bacterial infections, in Adams, J.H. and Duchen, L.W., Green Field's Neuropathology. Oxford University Press, New York.Pp.302-334.

Sáez-Llorens, X. and McCracken, G.H. (2003). "Bacterial Meningitis in Children". Lancet, 361(9375):2139-2148.

Sultan, B., Labadi, K., Guégan, J. F. and Janicot, S. (2005). Climate drives the meningitis epidemics onset in West Africa. Journal Plos Medicine. 2(1).

Tacon, C. L. and Flower, O. (2012). Diagnosis and Management of Bacterial Meningitis in the Paediatric Population. Emergency Medicine International. Available from http://dx.doi.org/10.1155/2012/320309.

Willey, J. M., Sherwood, L. M. and Christopher, W. V. (2008). Prescott, Harley and Klein's Microbiology. $7^{\text {th }}$ edition Published by McGraw-Hill Company, New Delhi, pp.950952

World Health Organization (2015). Meningococcal meningitis Available from http://www.who.int/mediacentre/factsheets/f s141/en/

www.apiweb.com Retrieved January 2017 